\title{
Use of a Temporary Shunt as a Salvage Technique for Distal Extremity Amputations Requiring Repair by Vessel Grafting during Critical Ischemia
}

\author{
Bilsev Ince, Mehmet Dadaci, Zeynep Altuntas \\ Department of Plastic, Reconstructive, and Aesthetic Surgery, Necmettin Erbakan University, Meram Faculty of Medicine, Konya, Turkey
}

Background Although the use of temporary shunts in proximal extremity amputations has been reported, no study has described the use of temporary shunts in distal extremity amputations that require vein grafting. Moreover, the total volume of blood loss when temporary shunts are used has not been reported. The aim of this study was to investigate the applicability of a temporary shunt for distal extremity amputations requiring repair by vessel grafting with an ischemia time of $>6$ hours. This study also aimed to determine the total volume of blood loss when temporary shunts were used.

Methods Patients who underwent distal major extremity replantation and/or revascularization with a vessel graft and who experienced ischemia for 6-8 hours between 2013 and 2014 were included in the study. A 6-Fr suction catheter was cut to $5 \mathrm{~cm}$ in length after the infusion of heparin, and secured with a 5-0 silk suture between the distal and the proximal ends of the artery. While bleeding continued, the bones were shortened and fixed. After the complete restoration of circulation, the arterial shunt created using the catheter was also repaired with a vein graft.

Results Six patients were included in this study. The mean duration of ischemia was 7.25 hours. The mean duration of suction catheter use during limb revascularization was 7 minutes. The mean transfusion volume was 7.5 units. No losses of the extremity were observed.

Conclusions This procedure should be considered in distal extremity amputations requiring repair by vessel grafting during critical ischemia.

Keywords Amputation / Replantation / Ischemia
Correspondence: Bilsev Ince Department of Plastic, Reconstructive, and Aesthetic Surgery, Meram Faculty of Medicine, Necmettin Erbakan University, 42080 Meram, Konya, Turkey

Tel: +90-332-223-6000-7791

Fax: $+90-332-323-6181$

E-mail: bilsevince@yahoo.com

This study was presented at the 36 th National Conference of the Society of Turkish Plastic Reconstructive and Aesthetic Surgeons on October 31, 2014.

No potential conflict of interest relevant to this article was reported.

Received: 7 Jan 2016 • Revised: 24 May 2016 • Accepted: 15 Jun 2016

pISSN: 2234-6163 • elSSN: 2234-6171 • https://doi.org/10.5999/aps.2016.43.6.544• Arch Plast Surg 2016;43:544-550

\section{INTRODUCTION}

Ischemia is one of the most common causes of cell injury. Irreversible damage due to prolonged severe ischemia leads to cell death, depending partially on the type of cells involved. In addition to traumatic injuries and the condition of the patient, one of the most important factors to consider in extremity replanta- tion is the duration of ischemia. In skeletal muscle, irreversible changes begin 4-6 hours after the onset of ischemia [1-5]. Replantation performed after this period remains controversial, even in patients who are otherwise eligible, and depends on factors such as the type of trauma, age, and the general condition of the patient, as ischemic damage is irreversible. Although blood flow may return to the ischemic tissue, revascularization after 
prolonged ischemia triggers events that may lead to damage not only to ischemic tissue, but also to other organ systems, which may be life-threatening $[1,2]$.

Many studies on temporary circulation have been performed with the goal of reducing the ischemic time in extremity injuries requiring revascularization [6-10]. Eger et al. [6] first reported the use of a temporary shunt in the management of arterial vascular injuries. Nunley et al. [7] then suggested the use of a Sundt carotid shunt as a temporary bridge between severed vascular ends to allow the rapid restoration of limb circulation. In other studies, femoral-to-radial, radial-to-radial, and cross-limb shunts have been proposed as options to provide temporary blood supply after injuries to the proximal extremities [8-10]. Although the use of temporary shunts in proximal extremity amputations has been reported [8-10], no study has described the use of temporary shunts in distal extremity amputations that require vein grafting. In addition, massive blood loss has been reported to occur with the use of temporary shunts [7], but the total volume of blood loss has not been reported.

We hypothesized that until the vessel graft is obtained and the bone fixation, providing reperfusion with a suction catheter may allow sufficient time for replantation in cases of critical ischemia, depending on the type of crush-avulsion injury. The aim of this study was to investigate the applicability of a temporary shunt for distal extremity amputations requiring repair by vessel grafting during an ischemia time of $>6$ hours. This study also aimed to determine the total volume of blood loss when temporary shunts were used.

\section{METHODS}

Six patients who underwent total or subtotal extremity amputations caused by crush-avulsion injuries between 2013 and 2014 were included in the study. The inclusion criteria for this study were being between 15 and 65 years of age, undergoing distal major extremity replantation and/or revascularization with a vessel graft, and experiencing 6-8 hours of ischemia. We excluded patients who underwent clean, sharp amputations as well as those with a hemoglobin level $<10 \mathrm{~g} / \mathrm{dL}$ on admission. We also excluded patients with associated life-threatening injuries, those who underwent multiple-level amputation or self-amputation, and cases of extreme contamination. All operations were performed synchronously and data were collected by two surgeons.

The patients were all stabilized hemodynamically and after either oral or written informed consented was obtained, the procedure was performed under general anesthesia. Two arteries were identified by dissecting both the distal and proximal amputation sites. The end of the artery that was visible from the

\section{Fig. 1. Illustration of the technique}

Suction catheter was secured with a silk suture between the distal and the proximal ends of the artery. Appearance of the artery with suction catheter.

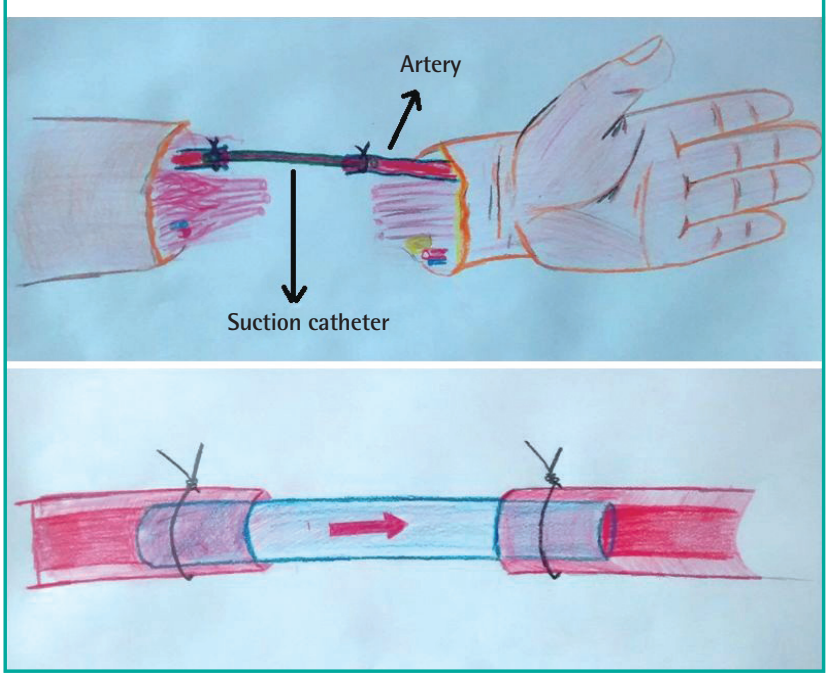

proximal side was cut until bleeding was observed. The same artery was then identified in the amputated portion. A 6-Fr suction catheter was cut to $5 \mathrm{~cm}$ in length after the infusion of heparin, and was secured with a 5-0 silk suture between the distal and the proximal ends of the artery (Fig. 1). The anesthesia team was informed that significant blood loss was expected after identification of the vessels. Circulation was controlled by opening the vessel clamp on the proximal end of the artery. Limb perfusion was observed within seconds. The color and temperature of the extremity improved, and capillary refill occurred within 10 minutes. While bleeding continued, the bones were shortened and fixed with plates, screws, or Kirchner wires. A second artery in the extremity was repaired using the saphenous vein taken from the leg by another surgeon using microsurgery and an $8 / 0$ polyamide monofilament suture. The patients were administered 5,000 units of intravenous heparin. When flow was observed in the second artery, a vascular clamp was applied to create an artery bypass. The most extensive vein that could be identified in the dorsal extremity was then repaired using a vein graft. After the complete restoration of circulation, the arterial bypass created using the catheter was also repaired with a vein graft.

Following limb perfusion, the other major veins, nerves, and tendons were repaired using appropriate techniques. Wounds were closed with primary sutures, a split-thickness skin graft, or a free flap depending on the condition of the patient. Hemoglobin levels, complete blood count, and blood gas levels were monitored during and after surgery. In order to maintain the mean hemoglobin levels at $10 \mathrm{~g} / \mathrm{dL}$, an erythrocyte suspension or 


\section{Fig. 2. A case involving an amputated hand}

(A) Appearance of the amputated hand. (B) Appearance of the forearm. (C) A 6-Fr suction catheter was cut to $5 \mathrm{~cm}$ in length after the infusion of heparin, and was secured with a 5-0 silk suture between the distal and the proximal ends of the artery. (D) Appearance of the hand 15 days after replantation.
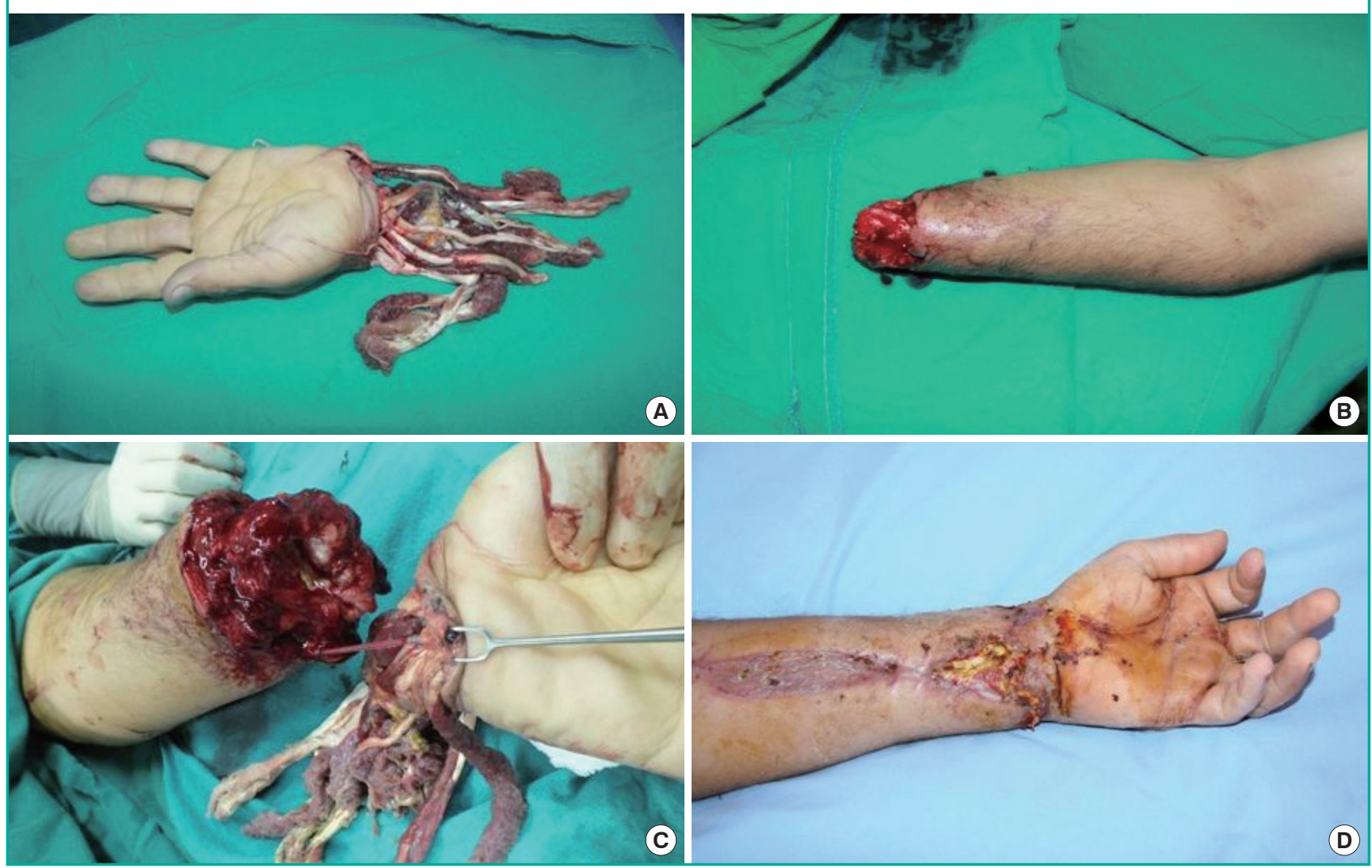

whole blood solution was administered to patients. An erythrocyte suspension was provided when blood transfusions could not be performed.

The extremities were kept elevated postoperatively, and blood flow was monitored by an hourly assessment of bleeding, evaluation for the presence of hematomas, nail capillary refill, and Doppler ultrasound. The medication regimen of all patients included 5,000 U of heparin taken three times daily, $300 \mathrm{mg}$ of acetylsalicylic acid taken once daily, $30 \mathrm{mg}$ of lansoprazole taken twice daily, 1,000 mg of amoxicillin clavulanate taken twice daily, and $100 \mathrm{mg}$ of pentoxifylline taken three times daily. A single dose of tetanus vaccine was also administered. Further treatment with $500 \mathrm{~mL}$ of dextran-40 over 24 hours was administered to patients in the first 3 postoperative days. Heparin treatment was stopped on postoperative day 7 , whereas acetylsalicylic acid treatment was continued for 1 month. Ten days after the initial procedure, patients underwent repeat debridement. Patients with a tissue defect after debridement underwent reconstructive surgery. After follow-up, patients without complications were discharged.

\section{RESULTS}

A total of 6 patients ( 5 male, 1 female) were included in the study. Their mean age was 39 years (range, 17-54 years). Vessel repair was performed in the lower extremity in 1 patient and in the upper extremity in 5 patients (Fig. 2). The mean follow-up period was 12 months (range, 10-18 months), and the mean length of the hospital stay was 18 days (range, 13-32 days). The mean duration of ischemia was 7.25 hours (range, 6-8 hours). After anesthetization in the operating room, the mean duration of suction catheter use for limb revascularization was 7 minutes (range, 4-12 minutes). The mean total operative time was 6 hours (range, 4-7 hours), and the mean transfusion volume was 7.5 units (range, 6-9 units) (Table 1). For soft tissue reconstruction, a split-thickness skin graft was used in 4 patients (Fig. 3), a local flap was used in 1 patient, and a free flap was used in $1 \mathrm{pa}-$ tient. Repeat debridement was performed in 4 patients. One patient who underwent foot amputation underwent revision for a circulatory disorder on postoperative day 8 , after which circulation was restored; however, necrosis was seen on the heel on follow-up, so reconstruction was performed with a sural flap 


\section{Table 1. Patient data}

\begin{tabular}{|lllcccc|}
\hline Patient no. & Age/Sex & Level of trauma & $\begin{array}{c}\text { Duration of } \\
\text { ischemia (hr) }\end{array}$ & $\begin{array}{c}\text { Perfusion } \\
\text { time (min) }\end{array}$ & $\begin{array}{c}\text { Transfusion volume } \\
\text { (unit) }\end{array}$ & Reconstruction \\
\hline 1 & 17/Male & Wrist & 8 & 5.5 & 7 & Skin graft \\
2 & 43/Male & Mid-forearm & 6 & 7.5 & 8 & Skin graft \\
3 & 38/Male & Ankle & 8 & 12 & 9 & Sural flap \\
4 & 48/Female & Mid-forearm & 6.5 & 7 & 7 & Free flap \\
5 & 54/Male & Wrist & 7.5 & 4 & 6 & Skin graft \\
6 & 34/Male & 1/3 distal forearm & 7.5 & 6 & 8 & Skin graft \\
\hline
\end{tabular}

\section{Fig. 3. A case involving an amputated hand}

(A) Appearance of the crush injury to the forearm. (B) Appearance of the hand after reconstruction. (C) Appearance of fingers during flexion. (D) Appearance of the key-pinch action.
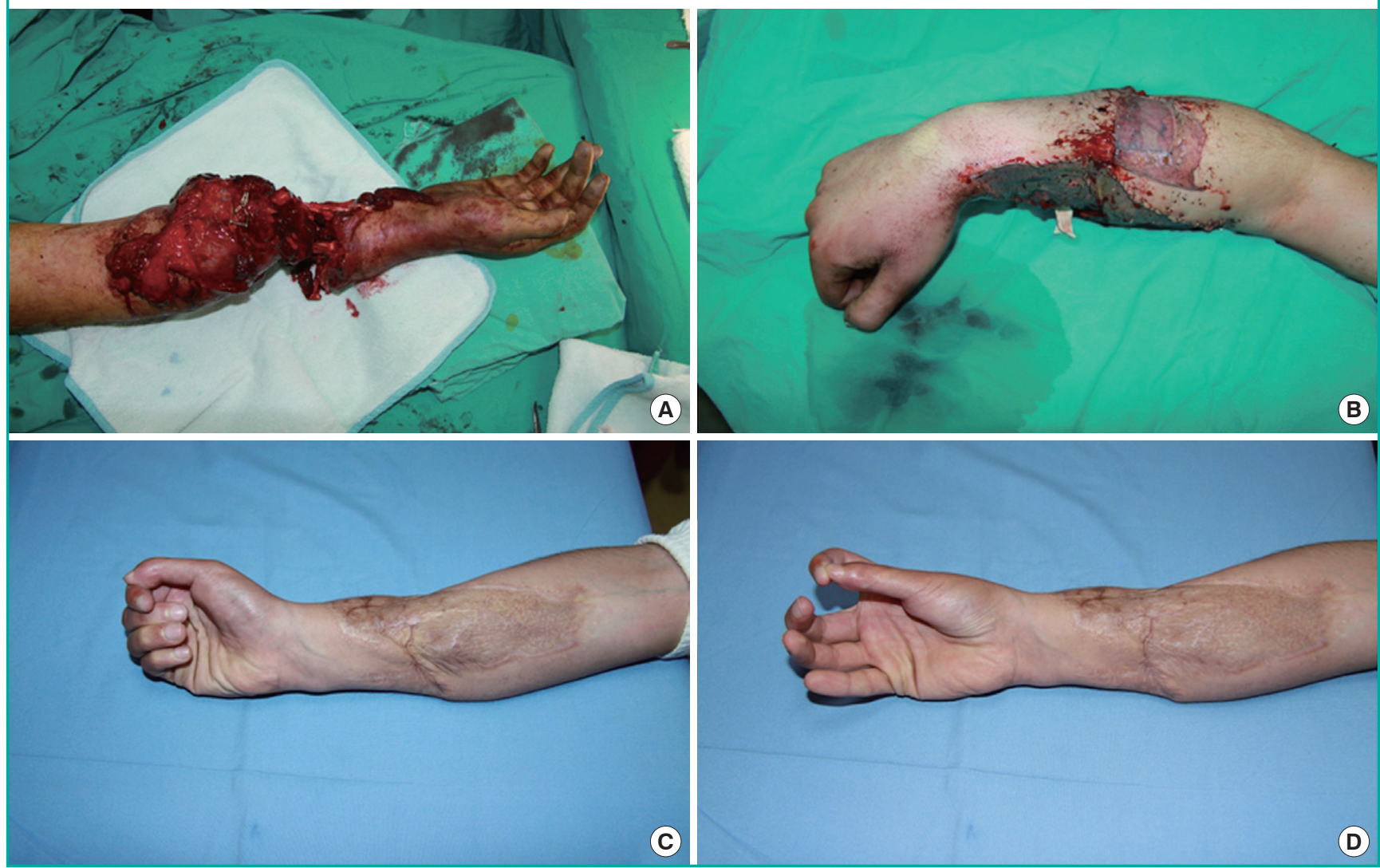

(Fig. 4). No extremity loss was observed in any patient.

\section{DISCUSSION}

In this study, we observed that a temporary shunt employing a suction catheter can be used successfully to treat distal extremity amputations caused by crush-avulsion injuries with an ischemia time of $>6$ hours.

Short-term ischemia after amputation causes reactive hyperemia and arterial vasodilation; however, in skeletal muscle ischemia lasting up to 4 hours, microcirculatory disorders and diffuse tissue edema develop with reperfusion [3]. Even if reperfu- sion occurs, edema further disrupts cell metabolism [2]. A previous study showed that the risk of injury after reperfusion increased with the duration of ischemia. Therefore, revascularization should be initiated as soon as possible in cases of amputation $[4,5]$.

In one of the first series describing a temporary shunt, Nunley et al. [7] successfully used an arterial shunt for revascularization in 3 total and 5 subtotal amputation cases. The only disadvantage they pointed out was bleeding; however, no information on the volume of blood loss, ischemia time, or the vascular graft used for the definitive artery repair was provided. This method was recommended as an adjunct to major arterial repair, which 


\section{Fig. 4. A case involving an amputated foot}

(A) Appearance of the amputated foot. (B) Appearance of the leg. (C) Appearance of necrosis on the heel. (D) Reconstruction was performed with a sural flap in this patient who underwent foot amputation.
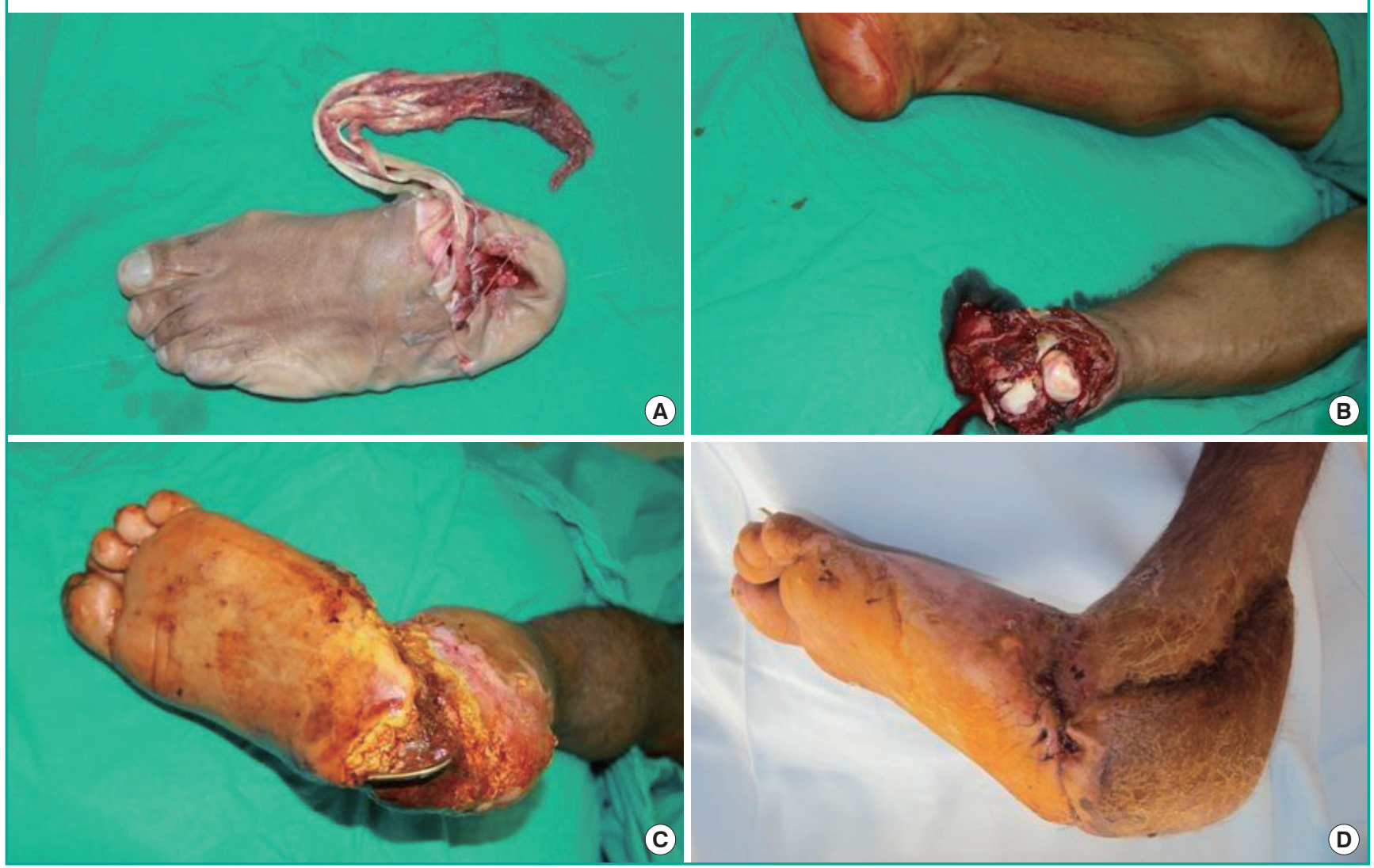

is associated with massive soft tissue and bony trauma. Suction

be critical for circulation to the distal hand or foot.

catheters, which we used in our technique, are less expensive and more easily available than arterial shunts. A silk suture was used to further secure the catheter to the vessel, and a vascular clamp was not necessary. Although Nunley et al. [7] suggested that arterial shunts could be used when the duration of ischemia was $>3$ hours, the mean duration was twice that length in our study.

Lee et al. [9] modified the arterial shunting technique in two ways. In his technique, the recipient artery for shunting was distal to the site of trauma, and the donor artery for shunting was the corresponding artery in the contralateral healthy limb. However, this cross-limb shunting used a distal donor peripheral artery, such as the radial or dorsalis pedis artery, to provide oxygenated blood flow. In addition, the oxygenated blood had to travel a long distance through the arterial pressure tubing. Both of these factors may have contributed to arterial flow obstruction due to the ease of clotting within the tubes. Frequent heparin flushes were necessary to maintain oxygenated blood flow. In addition, this method traumatized the undamaged radial or dorsalis pedis artery in the contralateral healthy limb, which may

Cavadas et al. [10] used temporary shunts in distal extremity amputations; the artery was ligated to the proximal stump after 10-15 minutes of perfusion and the catheter was removed. In our study, we did not stop circulation during the operation, as these two steps in the replantation process were accomplished by the shunt. However, the blood loss volume was $>2.5$ units per patient during the replantation.

If extreme hemodilution causes the flap to become significantly edematous, blood flow in the flap may be insufficient despite open arterial and venous anastomoses [11]. Menger et al. [12] determined that isovolemic hemodilution with a hematocrit level of $30 \%$ reduced reperfusion injury in ischemic muscles. In our study, blood was transfused in all patients to maintain hemoglobin levels $>10 \mathrm{~g} / \mathrm{dL}$.

Cadaveric studies have found the mean diameter of the brachial artery to be $3.96 \mathrm{~mm}$, the mean diameter of the radial artery to be $2.54 \mathrm{~mm}$, the mean diameter of the ulnar artery to be 2.12 $2.2 \mathrm{~mm}$, and the mean diameter of the deep palmar artery to be $0.8 \mathrm{~mm}[13,14]$. Although these values have been reported to vary to some extent among studies, a 6-Fr green suction catheter 
is $2 \mathrm{~mm}$ thick and is therefore thinner than all reported vessel diameters, except the deep palmar artery.

One of the biggest disadvantages of this technique is increased blood loss. Although massive hemorrhaging can occur with the use of temporary shunts, no study has quantified the extent of blood loss associated with temporary shunts. In a previous study, the mean volume of blood transfused was 3.29 units per finger replantation without venous anastomosis in patients who underwent amputations at the level of the distal interphalangeal joint [15]. A mean of 4.9 units of blood was transfused in successful major limb replantation operations [16], whereas the mean transfusion volume in our study was 7.5 units. Although blood loss does not appear to be advantageous, bleeding from the veins may assist in removing toxic metabolites from the body [7].

Temporary shunts can be applied to veins, as well as to arteries, to reduce blood loss; however, due to bleeding from many major and minor veins in the extremity, binding would require additional time. As a result, we did not use this method for veins in our study due to the already prolonged duration of ischemia. Spaced tourniquets have also been proposed to reduce blood loss in operations on the upper extremity [17]. Reperfusion due to tourniquet release for a short period and reapplication of the tourniquet (ischemic preconditioning) has been suggested to be useful [17]. This method reduced the no-reflow phenomenon at the level of capillary flow and leukocyte infiltration $[18,19]$. Although this technique increased tissue resistance to ischemia $[20,21]$ in already ischemic limbs, its effect on ischemia-reperfusion injuries remains unclear. Lee et al. [9] suggested that a tourniquet can be applied to the proximal end of the amputated limb and blood flow can be supplied from the distal portion of the amputated limb with a temporary shunt.

Placing a foreign substance into the lumen of blood vessels can increase the risk of thrombus formation. However, this has not been reported in any of the studies on temporary shunts. When the anastomosis does not work, extra time can be obtained for the re-establishment of an anastomosis using our technique, as circulation can be achieved before the artery is repaired with the vein graft.

Compared to a longer catheter, the suction catheter may decrease flow resistance. In all studies reporting the use of a temporary shunt, circulation within the amputated portion was allowed for 10-15 minutes, and then the steps of replantation were continued in a bloodless environment that was provided by the closure of the shunt [7-10]. However, in our study, the arterial circulation was never stopped during surgery. The transfusion of blood from other major extremities may be more appropriate in proximal extremity amputations, as a single artery is usually found in the proximal portion of the major extremities.
However, replantation and revascularization can be performed without damaging the intact limb when two arteries are injured, as indicated by our case series.

This technique should not be used in patients with massive hemorrhaging, those who are anemic, or when sufficient blood products for transfusion are not available. Catheter dislodgement during bone fixation and the disruption of the blood supply by thrombus formation are possible complications. Another disadvantage is the damage to the artery lumen by the catheter, which may result in vessel shortening. This can be resolved by obtaining a vessel graft that is $2 \mathrm{~cm}$ longer than the artery. However, this complication was not considered in our study, as this technique was part of our protocol for repair using vessel grafting. Sufficient time for replantation can be obtained with the temporary shunt technique using a suction catheter, allowing the duration of ischemia to be reduced. Thus, while circulation was achieved in a short time with the suction catheter, the second artery in the extremity was able to be repaired by vein grafting. This procedure should be considered in distal extremity amputations requiring repair by vessel grafting during critical ischemia.

\section{REFERENCES}

1. Suval WD, Duran WN, Boric MP, et al. Microvascular transport and endothelial cell alterations preceding skeletal muscle damage in ischemia and reperfusion injury. Am J Surg 1987;154:211-8.

2. Blaisdell FW. The pathophysiology of skeletal muscle ischemia and the reperfusion syndrome: a review. Cardiovasc Surg 2002;10:620-30.

3. Pedowitz RA. Tourniquet-induced neuromuscular injury: a recent review of rabbit and clinical experiments. Acta Orthop Scand Suppl 1991;245:1-33.

4. Park PO, Haglund U, Bulkley GB, et al. The sequence of development of intestinal tissue injury after strangulation ischemia and reperfusion. Surgery 1990;107:574-80.

5. Wehrens XH, Rouwet EV, oude Egbrink MG, et al. Effects of experimental lower-limb ischaemia-reperfusion injury on the mesenteric microcirculation. Br J Surg 2002;89:185-91.

6. Eger M, Golcman L, Goldstein A, et al. The use of a temporary shunt in the management of arterial vascular injuries. Surg Gynecol Obstet 1971;132:67-70.

7. Nunley JA, Koman LA, UrbaniakJR. Arterial shunting as an adjunct to major limb revascularization. Ann Surg 1981;193: 271-3.

8. Lee YC, Pan SC, Shieh SJ. Temporary femoral-radial arterial shunting for arm replantation. J Trauma 2011;70:1002-4.

9. Lee JW, Pan SC, Lin YT, et al. Cross-limb vascular shunting 
as an auxiliary to major limb revascularisation. Br J Plast Surg 2002;55:438-40.

10. Cavadas PC, Landin L, Ibanez J. Temporary catheter perfusion and artery-last sequence of repair in macroreplantations. J Plast Reconstr Aesthet Surg 2009;62:1321-5.

11. Kulahci Y, Bozkurt M, Sen H, et al. Mikrocerrahi ve anestezi. Turk J Plast Surg 2009; 17:97-104.

12. Menger MD, Sack FU, Barker JH, et al. Quantitative analysis of microcirculatory disorders after prolonged ischemia in skeletal muscle. Therapeutic effects of prophylactic isovolemic hemodilution. Res Exp Med (Berl) 1988;188:151-65.

13. Kiray A, Ergur I, Tayefi H, et al. Anatomical evaluation of the superficial veins of the upper extremity as graft donor source in microvascular reconstructions: a cadaveric study. Acta Orthop Traumatol Turc 2013;47:405-10.

14. Alagoz MS, Uysal AC, Tuccar E, et al. Muskulus palmaris brevis' in vasküler anatomisi. Turk Plast Surg 2008:16;65-8.

15. Chen YC, Chan FC, Hsu CC, et al. Fingertip replantation without venous anastomosis. Ann Plast Surg 2013;70:284-8.

16. Waikakul S, Vanadurongwan V, Unnanuntana A. Prognostic factors for major limb re-implantation at both immediate and long-term follow-up. J Bone Joint Surg Br 1998;80:102430.

17. Whetzel TP, Stevenson TR, Sharman RB, et al. The effect of ischemic preconditioning on the recovery of skeletal muscle following tourniquet ischemia. Plast Reconstr Surg 1997; 100:1767-75.

18. Jerome SN, Akimitsu T, Gute DC, et al. Ischemic preconditioning attenuates capillary no-reflow induced by prolonged ischemia and reperfusion. Am J Physiol 1995;268:H2063-7.

19. Akimitsu T, Gute DC, Korthuis RJ. Ischemic preconditioning attenuates postischemic leukocyte adhesion and emigration. Am J Physiol 1996;271:H2052-9.

20. Eastlack RK, Groppo ER, Hargens AR, et al. Ischemic-preconditioning does not prevent neuromuscular dysfunction after ischemia-reperfusion injury. J Orthop Res 2004;22: 918-23.

21. Orban JC, Levraut J, Gindre S, et al. Effects of acetylcysteine and ischaemic preconditioning on muscular function and postoperative pain after orthopaedic surgery using a pneumatic tourniquet. Eur J Anaesthesiol 2006;23:1025-30. 